\title{
Driver perceptions on taxi-sharing and dynamic pricing in taxi services: Evidence from Athens, Greece
}

\author{
Christina Milioti $^{\mathrm{a}}$, Konstantinos Kepaptsoglou ${ }^{\mathrm{b}, *}$, Konstantinos Kouretas ${ }^{\mathrm{b}}$, Eleni I. Vlahogianni ${ }^{\mathrm{b}}$ \\ ${ }^{a}$ University of West Attica, Greece \\ ${ }^{\mathrm{b}}$ National Technical University of Athens, Greece
}

A R T I C L E I N F O

\section{Keywords:}

Taxi

Taxi-sharing

Dynamic pricing

Econometric models

\begin{abstract}
A B S T R A C T
The taxi industry has changed dramatically during the last decade, as ridesourcing applications, ridesharing, and alternative pricing schemes have emerged, either as complementing or competitive services and strategies. After some years of familiarity with such trends, it is interesting to explore where the taxi industry stands with respect to possible service innovations. This paper explores the behavioral patterns of drivers, focusing on issues such as their preferred way of conducting business and their views on introducing taxi-sharing and dynamic pricing. Data collected from a face-to-face survey in Athens, Greece, are exploited and appropriate econometric models are developed for the purposes of the study. The analysis shows that young and/or educated drivers, as well as those who are familiar with new technologies, are more willing to accept innovations in taxi services. Results from a stated choice experiment show that on average 3.5 euros is the extra charge that the taxi market would accept to offer a taxi-sharing service. However, results reveal that the value of taxi-sharing varies across different groups of drivers. Overall, findings indicate that in the years to come, competition by other services (e.g., ridesharing) will force the taxi industry to adopt new models of operation and pricing.
\end{abstract}

\section{Introduction and background}

Taxi services inevitably play a vital role in integrated urban transportation systems (Milioti et al., 2015). Indeed, taxis offer safe and convenient door-to-door services, reduce demand for parking, and provide transportation to people with disabilities (Christoforou et al., 2012). During the last decade, the taxi industry has changed dramatically as emerging services (taxi booking applications, ridesharing, and so on) have emerged, either complementing or competing with taxis. In particular, the-often harsh-competition between taxis and ridesharing services has been widely investigated in recent years, highlighting the major determinants of traveler preference toward ridesharing, such as lower travel costs, use of web applications, and convenience in finding a ride (Vodopivec et al., 2015; Balac et al., 2015; Wang et al., 2012; Farren et al., 2016; Zhang et al., 2016; Heider et al., 2016). At the same time, the taxi industry worldwide opposes ridesharing services as these are considered to unfairly compete with taxis (Rayle et al., 2016).

There is no doubt that new technologies enhance service quality and can increase demand for taxi usage (Viegas, 2008; Hwang et al., 2006).
Several papers analyze taxi user perceptions about service quality and new taxi services including mobile booking applications (Khuong and Dai, 2016; Kumar and Kumar, 2016; Yao and Ding, 2011; Weng et al., 2017; Nguyen-Phuoc et al., 2020). Khuong and Dai (2016) concluded that the taxi industry should adopt novel applications and optimize the quality of services to compete with ridesharing. In this context, taxisharing schemes have emerged in London, New York, and Taipei (Tao, 2007; d'Orey and Ferreira, 2014). Taxi-sharing operates like ridesharing as it follows a real-time matching process of user requests to rides, but it uses taxis instead of private cars (Tao and Wu, 2008). The literature argues that taxi-sharing offers advantages over traditional taxi operations by decreasing produced vehicle-kilometers (and taxi emissions), increasing average taxi occupancy, and contributing to reduced fares and operating costs (Tao and Wu, 2008; d'Orey et al., 2012a,b; d'Orey and Ferreira 2014; Qian et al., 2017). However, as noted by Tao and Wu (2008), while taxi-sharing offers advantages to both taxi drivers and users, its acceptability largely depends upon economic parameters. Indeed, according to the literature, there is an expectation gap between driver and traveler perceptions with respect to taxi services (Belwal et al., 2013; Milioti et al., 2015). In a similar

\footnotetext{
* Correspondence to: Nationtal Technical University of Athens 5, Iroon Polytechniou str, Zografou Campus 15770, Attiki, Greecee.

E-mail addresses: c.milioti@uniwa.gr (C Milioti), kkepap@central.ntua.gr (K Kepaptsoglou), kostis.kouretas@gmail.com (K Kouretas), elenivl@central.ntua.gr (EI. Vlahogianni).
} 
context, while dynamic pricing (and especially congestion pricing) has been widely applied in the transport sector overall and particularly in ridesharing services, there is limited work on dynamic pricing in taxis. Only recent published work by Zeng and Oren (2014), Qian and Ukkusuri (2017), Jin et al. (2019), and Wei (2019) highlight the benefits of dynamic pricing in taxi services, such as increased revenues, improved accessibility and supply of services during peaks, and more attractive curbside hailing operations.

As in many places worldwide, new taxi services have been introduced in Athens, Greece, in recent years with some of them facing strong opposition by the local taxi industry (such as ridesourcing). Competitive ridesharing services were practically banned by government legislation in 2018 following strong protests by local taxi unions. Currently there are about 14,000 taxis operating in Athens (about 4 taxis per 1000 inhabitants) and the taxi market is strongly regulated. There is a cap on the number taxis and tariffs are set by the Greek government. National legislation strictly regulates taxi activity including operations, licensing, and requirements for vehicles, drivers, and owners. Taxi drivers may own a vehicle or act as employees to taxi owners; a license (medallion) is issued for vehicles (and not drivers) and taxi drivers must have a special driving permit. While obtaining this permit does not require special training, there are some qualitative requirements such as an adequate knowledge of the Greek language, having attended compulsory education, and being healthy enough to drive a taxi. Taxis may be hailed in the street, picked up at taxi stands, booked by phone, or booked through online applications. Different kilometer-based and traffic delay-waiting time tariffs are set, depending on the time of day (day, night) and service area. There are minimum charges per route and additional charges may apply (for luggage transportation, phone booking, etc.).

In this context, it is interesting to explore where Athens taxi drivers stand on existing taxi services as well as their views on potential new ones. This paper investigates the behavioral patterns of drivers with respect to their preferred ways of conducting business and their attitude toward new services and pricing strategies. The analysis was based on data collected from a face-to-face survey in Athens. Appropriate econometric models were developed to determine the factors that affect driver acceptability of taxi-sharing and dynamic pricing. Quantitative results provide useful information to the taxi industry for establishing efficient policy measures that match the new market conditions, considering driver expectations. The remainder of the paper is structured as follows: the next section presents the data collection effort, while subsequent sections introduce the models developed and analyze and discuss the results. The paper concludes with major findings of the analysis.

\section{Data collection}

Data were collected through an in-person survey of Athens taxi drivers in different locations around the city. A random sampling approach was adopted for choosing responders. Responses were anonymous and the average time to complete the questionnaire ranged from four to five minutes. This minimized the effort and time of the respondents and increased the reliability and validity of their responses. The survey response rate was approximately $62 \%$. After a preliminary review of collected questionnaires for possible inconsistencies, a final sample of 293 valid answer sets was used for further analyses (approximately $2.1 \%$ of 14,000 taxis currently operating in Athens).

\section{Questionnaire contents}

The questionnaire was developed to cover a wide range of subjects on the taxi profession and services with a specific focus on taxi driver attitude toward new services. Questions referred to the socioeconomic attributes of drivers, supply and working conditions, operational costs, taxi booking and hailing methods, the use of online booking
Table 1

Socioeconomic characteristics of taxi drivers.

\begin{tabular}{lcl}
\hline Question & Answer & Percentage (\%) \\
\hline \multirow{2}{*}{ Gender } & N/A & $0.7 \%$ \\
& Male & $94.9 \%$ \\
Age & Female & $4.4 \%$ \\
& $18-25$ & $0.3 \%$ \\
& $26-35$ & $9.6 \%$ \\
& $36-45$ & $27.3 \%$ \\
Ownership status & $46-55$ & $39.6 \%$ \\
Years in profession & $56-65$ & $21.5 \%$ \\
& $>65$ & $1.7 \%$ \\
& Owner & $49.5 \%$ \\
& Driver & $50.5 \%$ \\
& $<5$ & $19.1 \%$ \\
& $5-9$ & $22.5 \%$ \\
& $9-19$ & $30.7 \%$ \\
& $20-30$ & $19.8 \%$ \\
\hline
\end{tabular}

applications, and attitudes on taxi-sharing and dynamic pricing. Most questions required answers in a 5-point Likert scale or binary answers (e.g., Yes/No, Case A/Case B). A question on available taxi booking/ hailing methods demanded an order of preference among available options. In addition, the questionnaire included a stated-preference experiment, which included six choice sets of alternative trip time, trip revenue, and taxi-sharing option combinations; this experiment was developed to valuate taxi-sharing for taxi drivers.

\section{Descriptive statistics}

Table 1 presents the sociodemographics of the sample. Among drivers who took part in this survey, the majority are males (94.9\%), half of them are taxi owners (49.5\%), and $39.6 \%$ fall between 46 and 55 years of age. Professional experience varies as indicated by the years spent in the taxi industry, with most respondents working in the taxi sector between 9 and 19 years.

\section{Supply and working conditions}

A typical taxi driver in Athens works more than $10 \mathrm{~h}$ per day $(92.8 \%$ of drivers) according to the survey findings (Table 2), while during a typical day, $78.5 \%$ of drivers undertake $10-24$ trips. During the last two years, $47.1 \%$ of survey participants stated that demand for taxi services has increased, while $32.1 \%$ stated that it has remained about the same.

Table 2

Travel and work data.

\begin{tabular}{|c|c|c|}
\hline Question & Answer & Percentage (\%) \\
\hline Average hours of work per & N/A & $0.3 \%$ \\
\hline \multirow[t]{6}{*}{ day } & $<8$ & $2.4 \%$ \\
\hline & 9 & $4.4 \%$ \\
\hline & 10 & $13.0 \%$ \\
\hline & 11 & $12.6 \%$ \\
\hline & 12 & $32.1 \%$ \\
\hline & $>12$ & $35.2 \%$ \\
\hline \multirow[t]{7}{*}{ Trips per day } & $<5$ & $3.8 \%$ \\
\hline & $5-9$ & $8.2 \%$ \\
\hline & $10-14$ & $30.0 \%$ \\
\hline & $15-19$ & $25.6 \%$ \\
\hline & $20-24$ & $22.9 \%$ \\
\hline & $25-30$ & $5.8 \%$ \\
\hline & $>30$ & $3.8 \%$ \\
\hline \multirow[t]{5}{*}{$\begin{array}{l}\text { Demand change during the } \\
\text { last } 2 \text { years }\end{array}$} & $\begin{array}{l}1 \text { (large } \\
\text { reduction) }\end{array}$ & $8.5 \%$ \\
\hline & 2 & $12.3 \%$ \\
\hline & 3 & $32.1 \%$ \\
\hline & 4 & $41.0 \%$ \\
\hline & 5 (large increase) & $6.1 \%$ \\
\hline
\end{tabular}


Table 3

Taxi booking and hailing methods.

\begin{tabular}{lllll}
\hline $\begin{array}{l}\text { Ranking } \\
\text { Order }\end{array}$ & Curbside & Taxi Stand & Web Apps & Phone Call \\
\hline 1 & & & & \\
2 & $26.1 \%$ & $19.0 \%$ & $35.6 \%$ & $18.3 \%$ \\
3 & $33.6 \%$ & $33.2 \%$ & $12.9 \%$ & $5.4 \%$ \\
4 & $16.3 \%$ & $11.2 \%$ & $4.7 \%$ & $3.4 \%$ \\
$*$ & $2.0 \%$ & $1.7 \%$ & $0.0 \%$ & $1.7 \%$ \\
\hline
\end{tabular}

*Selected, regardless of the order of preference.

\section{Taxi booking and hailing methods}

Several taxi hailing methods were considered in the survey (curbside or taxi stand pickup, online booking applications, and phone hailing) and drivers were asked to rank their options in order of preference. Picking up customers from the curbside was found to be the prevailing option, selected by $77.7 \%$ of drivers (Table 3 ). Taxi stands followed with $64.9 \%$ and online taxi booking applications were chosen by $53.0 \%$ of respondents. This is probably related to the fact that taxi booking applications have not yet reached their full potential. Indeed, older customers and taxi drivers are not always familiar with smartphone applications and therefore reluctant to use taxi booking applications. However, those who included online taxi apps usually ranked them first (35.6\% of drivers).

\section{Use of online taxi booking applications}

Drivers preferring online booking applications included reasons behind their preference for using them and perceived advantages or disadvantages (Table 4). Security ranks as a major reason for using these applications, selected by $27.6 \%$ of respondents. Still, almost half of the sample (48.1\%) does not use taxi booking applications at all. According to drivers' perceptions, the cost of using these apps is high; specifically, $18.1 \%$ of the drivers believe they are expensive. Most popular taxi booking apps in Athens impose a commission fee of more than $10 \%$ per ride booked through their service.

\section{Taxi-sharing and dynamic pricing perception}

Taxi drivers seem reluctant toward adopting taxi-sharing, even if this means a $10 \%$ increase in revenues, since $59.1 \%$ of those surveyed disagree with this option (Fig. 1). Furthermore, a high percentage (47.8\%) strongly disagrees with the introduction of a taxi-sharing service. Although taxi-sharing is not currently allowed in Athens, it is unofficially performed by a few drivers who pick up non-associated travelers with similar destinations at taxi stands and the curbside.

Table 4

Use of online taxi booking applications.

\begin{tabular}{lll}
\hline Question & Answer & Percentage (\%) \\
\hline $\begin{array}{c}\text { Reasons for choosing online } \\
\text { taxi booking applications }\end{array}$ & $\begin{array}{l}\text { Question not } \\
\text { answered }\end{array}$ & $1.0 \%$ \\
& $\begin{array}{l}\text { Lower cost } \\
\text { Increased }\end{array}$ & $3.1 \%$ \\
& security & $27.6 \%$ \\
& Social & \\
& interaction & $1.0 \%$ \\
& Lower vacant & $19.1 \%$ \\
mow expensive would you say & mon-user & \\
web apps are? & 1 (not at all) & $48.1 \%$ \\
& 2 & $9.2 \%$ \\
& 3 & $29.4 \%$ \\
& 4 & $20.8 \%$ \\
& 5 (very much) & $18.1 \%$ \\
\hline
\end{tabular}

Unlike drivers, customers sharing the taxi receive no economic benefit from this (illegal) practice. Nevertheless, drivers probably feel that allowing organized taxi-sharing will complicate their service and add workload without offering much economic incentive. Furthermore, they have no insight into the potentially smooth operation of such a service if based on a ridesourcing application.

As shown by Fig. 2, drivers are not keen to adopt dynamic pricing, with $47.1 \%$ of respondents strongly disagreeing and an additional $19.8 \%$ disagreeing, raising the total opposing percentage to $66.9 \%$.

\section{Models}

\section{Driver acceptability models}

Two binary logistic discrete choice models were developed to further explore driver acceptability of taxi-sharing and dynamic pricing. Drivers' demographic characteristics, working conditions, and perceptions on operational costs were used as explanatory variables.

The first model (Table 5) investigates driver willingness to accept taxi-sharing. The dependent variable takes the value of 1 when the driver is willing to accept taxi-sharing and 0 otherwise. Educational level and age are major explanatory factors: younger taxi drivers and the more educated are willing to accept a taxi-sharing service. Model results indicate that those who provide internet access in their taxis have an increased probability of accepting a taxi-sharing scheme. Drivers who believe that the existence of competitors, including ridesharing companies, is one of the most important problems that the taxi industry faces are also willing to accept taxi-sharing. Thus, they probably feel that to compete with ridesharing companies they must provide new services, such as taxi-sharing. Finally, those who state that the cost of a taxi license is expensive are more likely to accept such a scheme.

The second model (Table 6) focuses on the acceptability of dynamic pricing, in which charges are regulated according to the demand for taxi services. The dependent variable takes the value of 1 when the driver is willing to accept such a scheme and 0 otherwise. Familiarity with technology positively affects the willingness to accept dynamic pricing. The same applies for the taxi drivers who offer internet access in their taxis. As the percentage of vacant kilometers rises, the willingness to accept a dynamic pricing scheme also increases. This finding probably indicates that taxi drivers believe a dynamic pricing scheme could distribute customers more equally among taxis and thus reduce their vacant kilometers. On the other hand, taxi drivers who prefer to pick up clients at taxi stands are less likely to accept dynamic pricing; this is expected since taxis in these cases are booked in a first-come, first-served order.

\section{A stated preference experiment on taxi-sharing}

As part of the questionnaire, choice sets defined by the attribute combinations of travel time, revenue, and taxi-sharing for a typical ride in Athens, Greece, were presented to respondents. The specific attribute levels were defined following a discussion with members of the Athens taxi industry and are presented in Table 7 . It is noted that when taxisharing is set to 0 (no taxi-sharing), it is implied that the total amount of time and revenue is a result of two distinct pick-ups and trips.

The stated choice experiment was designed using the statistical software R (Aizaki and Nishimura, 2008). The use of orthogonal fractional-factorial design was applied and six choice sets were created; an example of a choice set is presented in Table 8. To explain the response procedure to the taxi drivers, a choice set was presented at the beginning of the stated preference experiment.

Based on these choice sets, the stated-preference experiment was exploited for describing driver response to taxi-sharing under different time travel and revenue scenarios. The drivers evaluated available alternatives offered, compared their attractiveness, and decided upon their preferred case. A multinomial logit (MNL) approach was adopted 


\section{Do you agree on taxi-sharing with lower passenger fare but higher revenues for drivers $(10 \%)$ ?}

$60.00 \%$
$50.00 \%$
$40.00 \%$
$30.00 \%$
$20.00 \%$
$10.00 \%$
$0.00 \%$

\section{$47.80 \%$}

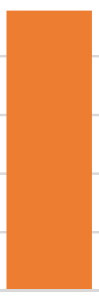

$17.70 \%$

(1) Strongly
Disagree

(2) Disagree

(3) Neutral

(4) Agree

(5) Strongly Agree

Fig. 1. Driver attitude toward taxi-sharing.

Do you agree with dynamic pricing, i.e., lower prices when demand is low and higher prices when demand is high?

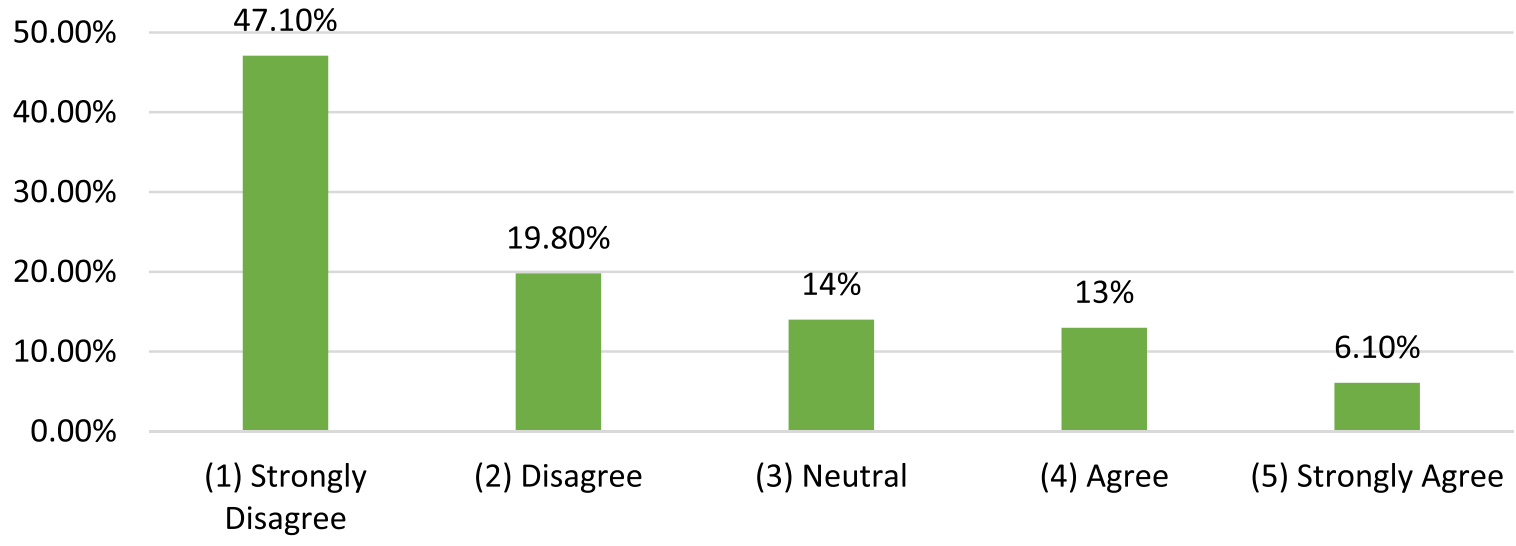

Fig. 2. Driver attitude toward dynamic pricing.

Table 5

Taxi-sharing acceptability model.

\begin{tabular}{|c|c|c|c|}
\hline Variables & Coefficient $\beta$ & Prob. & Odds \\
\hline Educational level (from $1=$ middle school to $5=$ master, $\mathrm{PhD}$ ) & 0.369 & 0.031 & 1.447 \\
\hline Age $(1=<18 ; 2=18-25 ; 3=26-35,4=36-45,5=46-55,6=56-65,7=>65)$ & -0.381 & 0.010 & 0.683 \\
\hline Traveled $\mathrm{km}$ per day $(1=<150 ; 2=150-189 ; 3=190-219,4=220-249,5=250-279,6=280-300,7=>300)$ & -0.221 & 0.021 & 0.802 \\
\hline Percentage of vacant $\mathrm{km}(1=0-20 \% ; 2=21-40 \% ; 3=41-60 \%, 4=>60 \%)$ & 0.246 & 0.101 & 1.278 \\
\hline Revenue per day $(1=<50 ; 2=50-70 ; 3=71-90,4=91-110,5=111-130,6=131-150,7=>150)$ & 0.163 & 0.115 & 1.177 \\
\hline Existence of competition is a problem (from $1=$ strongly disagree to $5=$ strongly agree) & 0.266 & 0.051 & 1.304 \\
\hline Poor quality of passengers is a problem (from $1=$ strongly disagree to $5=$ strongly agree) & -0.324 & 0.017 & 0.723 \\
\hline Low availability of taxi stands is a problem (from $1=$ strongly disagree to $5=$ strongly agree) & -0.286 & 0.014 & 0.751 \\
\hline Taxi license cost (from $1=$ not at all to $5=$ very much) & 0.373 & 0.006 & 1.452 \\
\hline Internet availability ( $1=$ yes; $0=$ otherwise $)$ & 0.524 & 0.072 & 1.689 \\
\hline Taxi as full-time or part-time job ( $1=$ part-time; $0=$ otherwise $)$ & 1.040 & 0.171 & 2.828 \\
\hline Constant & -2.463 & 0.071 & \\
\hline Nagelkerke $\mathrm{R}^{2}=0.206$ & & & \\
\hline
\end{tabular}

Table 6

Dynamic pricing acceptability model.

\begin{tabular}{|c|c|c|c|}
\hline Variables & Coefficient $\beta$ & Prob. & Odds \\
\hline Age $(1=<18 ; 2=18-25 ; 3=26-35,4=36-45,5=46-55,6=56-65,7=>65)$ & -0.247 & 0.109 & 0.781 \\
\hline Percentage of vacant km ( $1=0-20 \% ; 2=21-40 \% ; 3=41-60 \%, 4=>60 \%)$ & 0.419 & 0.006 & 1.520 \\
\hline Poor quality of passengers is a problem (from $1=$ strongly disagree to $5=$ strongly agree) & -0.392 & 0.003 & 0.676 \\
\hline Internet availability $(1=$ yes; $0=$ otherwise $)$ & 0.495 & 0.096 & 1.641 \\
\hline Technology familiarity (from $1=$ not at all to $5=$ very $\mathrm{much}$ ) & 0.303 & 0.045 & 1.353 \\
\hline Low availability of taxi stands is a problem (from $1=$ strongly disagree to $5=$ strongly agree) & -0.737 & 0.052 & 0.479 \\
\hline Constant & -1.073 & 0.258 & 0.342 \\
\hline Nagelkerke $\mathrm{R}^{2}=0.142$ & & & \\
\hline
\end{tabular}


Table 7

Attributes and levels of the stated choice experiment.

\begin{tabular}{ll}
\hline Attributes & Values \\
\hline Travel time (X1) & $20,30,40,45 \mathrm{~min}$ \\
Total revenue (X2) & $10,12,14,16,20 €$ \\
Taxi-sharing (X3) & 0 (no taxi-sharing), 1 (taxi-sharing) \\
\hline
\end{tabular}

Table 8

Choice set example.

\begin{tabular}{lll}
\hline Attributes & Group 2 & \\
\cline { 2 - 3 } & Choice A & Choice B \\
\hline Travel time (X1) & 30 min & 45 min \\
Total revenue (X2) & $14 €$ & $20 €$ \\
Ridesharing (X3) & 1 & 0 \\
\hline
\end{tabular}

for modeling stated driver preferences: attractiveness of each alternative is represented by a utility function (Ortuzar and Willumsen, 2011). Drivers aim at maximizing their utility, according to the principle of random utility maximization (Ben-Akiva and Lerman, 1985; McFadden, 1978). In cases of unlabeled experiments, the constant term is not included in the utility function (Hensher et al., 2005). The mathematical formulation of the utility function is the following:

$V_{i}=\beta_{\text {revenue }} \cdot$ revenue $+\beta_{\text {time }}$.time $+\beta_{\text {taxisharing }} \cdot$ taxisharing

where revenue, time and taxisharing represent the attributes of each alternative and $\beta_{\text {revenue, }} \beta_{\text {time }}$, and $\beta_{\text {taxisharing }}$ are coefficients indicating the contribution of each attribute to the overall utility. Once model coefficient estimates were obtained, willingness-to-receive-payment (WTRP) measures were calculated as the ratio of these corresponding coefficients (Washington et al., 2010).

$W T R P_{\text {taxisharing }}=\frac{\beta_{\text {taxisharing }}}{\beta_{\text {revenue }}}, W T P_{\text {time }}=\frac{\beta_{\text {time }}}{\beta_{\text {revenue }}}$
Table 9 presents the model results. First, model parameters were calculated for the entire sample to determine how much drivers value on average taxi-sharing, travel time, and revenues. Next, the sample was segmented into distinct categories based on driver characteristics such as age, use of online booking applications, and taxi ownership. This was done to explore variations in driver responses depending on individual personal and professional characteristics. For the age-based segmentation, respondents were divided into two groups, namely young and old. The barrier for this segmentation was age 45 .

The estimated parameters are found to be significant at the $1 \%$ significance level and with the expected signs. The results of the model analysis show that, in general, a driver does not prefer taxi-sharing $\left(\beta_{\text {rideshare }}<0\right)$ and, as expected, aims for lower travel times $\left(\beta_{\text {time }}<0\right)$ and higher revenues $\left(\beta_{\text {revenue }}>0\right)$ ). Online booking application users appear less willing to accept taxi-sharing than non-users. This finding is probably related to the fact that taxi drivers believe that taxi-sharing works effectively only when additional customers are picked up during the route and not when taxi-sharing is preprogrammed via a web application. Also, drivers probably believe that if they seek customers at the curbside instead of using a web application, they can minimize their vacant vehicle-kilometers. Travel time and revenue attract similar responses from both categories. Young drivers are slightly more willing to accept taxi-sharing but are also more sensitive when it comes to time and revenues. When divided into categories depending on taxi ownership, drivers who own a taxi license appear less interested in taxisharing, but also are less affected by travel time and revenues than those who drive taxis as employees.

Table 10 presents the values of time and taxi-sharing for the various models developed. With respect to taxi-sharing, the minimum extra charge that taxi drivers would accept to work on a taxi-sharing basis is listed. On average, this amount is estimated at $3.46 €$ (pooled sample). The results indicate that young drivers are more willing to accept a taxi-sharing system at a lower price per route. This finding confirms the results of the binary logistic model presented in the previous section (Table 5); young drivers have an increased probability of implementing a taxi-sharing scheme compared to older drivers. Interestingly, drivers who use web applications would price higher a ridesharing route compared to those

Table 9

MNL model results for stated preference experiment.

\begin{tabular}{|c|c|c|c|c|}
\hline Variable & \multicolumn{4}{|l|}{ All } \\
\hline Taxi-sharing (X1) & -1.829552 & & -7.3314 & \\
\hline Revenue (X3) & 0.528186 & & 9.2277 & \\
\hline Log-likelihood: & -940.47 & & & \\
\hline \multirow[t]{2}{*}{ Number of questionnaires } & 293 & & & \\
\hline & With App & & Without App & \\
\hline Time (X2) & -0.25301 & -6.3719 & -0.212634 & -5.8917 \\
\hline Revenue (X3) & 0.538954 & 6.5907 & 0.521528 & 6.4686 \\
\hline Log-likelihood: & -496.94 & & -442.72 & \\
\hline \multirow[t]{2}{*}{ Number of questionnaires } & 151 & & 139 & \\
\hline & Young & & Old & \\
\hline Variable & $\beta$ - Estimate & $t$-value & $\beta$-Estimate & t-value \\
\hline Taxi-sharing (X1) & -1.532517 & -3.8883 & -2.021611 & -6.1661 \\
\hline Variable & $\beta$-Estimate & t-value & $\beta$-Estimate & $t$-value \\
\hline Taxi-sharing (X1) & -1.905372 & -5.5157 & -1.77761 & -4.8783 \\
\hline Time (X2) & -0.208488 & -5.8288 & -0.257505 & -6.3953 \\
\hline Revenue (X3) & 0.462031 & 5.8286 & 0.593459 & 7.1176 \\
\hline Log-likelihood: & -452.22 & & -484 & \\
\hline Number of questionnaires & 145 & & 148 & \\
\hline
\end{tabular}


Table 10

Values of taxi-sharing and travel time.

\begin{tabular}{lll} 
& $\begin{array}{l}\text { Taxi-Sharing } \\
\text { (X1) }\end{array}$ & $\begin{array}{l}\text { Travel Time } \\
\text { (X2) }\end{array}$ \\
\hline $\begin{array}{l}\text { Pooled sample } \\
\text { With online taxi booking }\end{array}$ & -3.46 & -0.44 \\
$\quad \begin{array}{l}\text { application } \\
\text { Without online taxi booking }\end{array}$ & -3.72 & -0.47 \\
$\quad$ application & -3.17 & -0.41 \\
Old & & \\
Young & -3.87 & -0.42 \\
Owner & -2.84 & -0.47 \\
Driver & -3.53 & -0.39 \\
& -3.41 & -0.49 \\
\hline
\end{tabular}

who do not. This is probably related to the fact that most drivers stated that the cost of using online taxi booking applications is high and thus believe that this should be reflected in the final charge. Taxi license owners and drivers value almost equally taxi-sharing route; however, as expected, value of time is higher for the taxi drivers.

\section{Conclusions}

In this paper, taxi driver opinions on new taxi services were explored. Two binary logistic models were developed to analyze driver acceptability of taxi-sharing and dynamic pricing and to determine the factors that increase/decrease their acceptance. Model results indicate that young drivers, those with a high level of education, and those familiar with technology are more willing to accept such schemes. In addition, a high percentage of vacant kilometers increases acceptability in both models. Model results also indicate that drivers who believe the existence of competitors (including ridesharing companies) is one of the most important problems the taxi market faces are more willing to accept a taxi-sharing scheme. This finding implies that there is a group of drivers who advocate that the taxi market should adopt novel applications in order to compete efficiently with ridesharing companies.

To further investigate the acceptability of taxi-sharing, a stated preference exercise estimated taxi-sharing and travel time values for taxi drivers. Results show that on average the taxi market would accept an extra charge of $3.5 €$ to offer a taxi-sharing service. However, results also reveal that the value of ridesharing varies across different groups of drivers. Young drivers are more likely to accept the ridesharing system at a lower price. Overall, findings indicate that as younger professionals enter the taxi industry, acceptability of new services will improve. Eventually competition by other services, (e.g., ridesharing) will also force the taxi industry to adopt new models of operation and pricing. These new models may be further promoted by regulating authorities, as the reduction of total and vacant taxi vehicle-kilometers produces the direct benefits of reducing traffic congestion and the emissions generated by cruising taxis.

\section{Declaration of Competing Interest}

The authors declare that they have no known competing financial interests or personal relationships that could have appeared to influence the work reported in this paper.

\section{Acknowledgments}

This study was funded by BEAT S.A. (http://thebeat.com).

\section{References}

Aizaki, H., Nishimura, K., 2008. Design and analysis of choice experiments using R: a brief introduction. Agric. Inf. Res. 17, 86-94.

Balac, M., Ciari, F., Axhausen, K.W., 2015. Carsharing demand estimation: Zurich, Switzerland, area case study. Transp. Res. Rec. 2563 (1), 10-18.

Belwal, R., Minhans, A., Al-Balushi, A.-M., 2013. Perception of taxi services in Oman-a cross examination of citizens' and taxi drivers' perception. J. Technol. 65 (3), 33-39.
Ben-Akiva, M., Lerman, S.R., 1985. Discrete Choice Analysis: Theory and Applications Travel Demand. The MIT Press, Cambridge.

Christoforou, Z., Milioti, C., Perperidou, D., Karlaftis, M.G., 2012. Investigation of taxi travel time characteristics. Adv. Transp. Stud. 27, 17-30.

d'Orey, P.M., Fernandes, R., Ferreira, M., 2012a. Reducing the environmental Impact of taxi operation: the taxi-sharing use case. In: Proceedings of the 12th International Conference on ITS Telecommunications. 5-8 November, Taipei, Taiwan, pp. 319-323.

d'Orey, P.M., Fernandes, R., Ferreira, M., 2012b. Empirical evaluation of a dynamic and distributed taxi-sharing system. In: Proceedings of the 15th International IEEE Conference on Intelligent Transportation Systems. Anchorage, Alaska, pp. 140-146.

d'Orey, P.M., Ferreira, M., 2014. Can ride-sharing become attractive? A case study of taxisharing employing a simulation modelling approach. IET Intell. Transp. Syst. 9 (2), $210-220$.

Farren, M., Koopman, C., Mitchell, M., 2016. Rethinking Taxi Regulations: The Case for Fundamental Reform. Report, Mercatus Center at George Mason University.

Heider, B., Simões, C.S., Cizmar, I., Burmester, M., 2016. Uber versus Taxi: Generation Y's Perception of Taxi and Uber Services in Lisbon. Seminar Paper, Grin Verlag, Berlin.

Hensher, D.A., Rose, J.M., Greene, W.H., 2005. Applied Choice Analysis - A Primer. Cambridge University Press, New York.

Hwang, K.P., Wu, K.H.-C., Jian, R.-J., 2006. Modeling consumer preference for global positioning system-based taxi dispatching service: case study of Taichung City, Taiwan. Transp. Res. Rec. J. Transp. Res. Board 1971, 99-106.

Jin, Y.-M., Ye, X.F., Liu, W.L., Wang, T., Wang, H., 2019. Dynamic pricing model for cruising taxicab based on system dynamics. Adv. Mech. Eng. 11 (2), 1-8.

Khuong, M.N., Dai, N.Q., 2016. The factors affecting customer satisfaction and customer loyalty - a study of local taxi companies in Ho Chi Minh City, Vietnam. Int. J. Innov. Manag. Technol., 7(5).

Kumar, P.K., Kumar, N.R., 2016. A study on factors influencing the consumers in selection of cab services. Int. J. Soc. Sci. Humanit. Res. 4 (3), 557-561.

McFadden, D., 1978. Modeling the choice of residential location. In: Karlqvist, A., Lundqvist, L., Snickars, F., Weibuill, J. (Eds.), Spatial Interaction theory and Residential Location. NorthHolland, Amsterdam.

Milioti, C., Karlaftis, M., Spyropoulou, D., 2015. The impact of financial recession on taxi market: perceptions of travelers and taxi drivers. Transp. Res. Rec. J. Transp. Res. Board 2536 (1), 67-70.

Nguyen-Phuoc, D.Q., Su, D.N., Tran, P.T.K., Le, D.T.T., Johnson, L.W., 2020. Factors influencing customer's loyalty towards ride-hailing taxi services-a case study of Vietnam. Transp. Res. Part A Policy Pract. 134, 96-112.

Ortuzar, J., Willumsen, L.G., 2011. Modelling Transport. John Wiley \& Sons.

Qian, X., Ukkusuri, S., 2017. Time-of-day pricing in taxi markets. IEEE Trans. Intell. Transp. Syst. 18 (6), 1610-1622.

Qian, X., Zhang, W., Ukkusuri, S.V., Yang, C., 2017. Optimal assignment and incentive design in the taxi group ride problem. Transp. Res. Part B Methodol. 103, 208-226.

Rayle, L., Dai, D., Chan, N., Cervero, R., Shaheen, S., 2016. Just a better taxi? A survey-based comparison of taxis, transit, and ridesourcing services in San Francisco. Transp. Policy 45, $168-178$.

Tao, C.-C., 2007. Dynamic taxi-sharing service using intelligent transportation system technologies. In: Proceedings of the International Conference on Wireless Communications, Networking and Mobile Computing, New York, USA, pp. 3209-3212.

Tao, C., Wu, C., 2008. Behavioral responses to dynamic ridesharing services - the case of taxisharing project in Taipei. In: Proceedings of the 2008 IEEE International Conference on Service Operations and Logistics, and Informatics, 2, pp. 1576-1581.

Viegas, J.M., 2008. Taxis: bridging the gap between individual and collective transport. Public Transp. Int. 5 (2), 6-7.

Vodopivec, N., Tobias, D., Miller-Hooks, E., Schonfeld, P., Mohebbi, M., 2015. Taxis as a recourse option for ridesharing services. Transp. Res. Rec. J. Transp. Res. Board 2563 (1), 86-97.

Wang, M., Martin, E.W., Shaheen, S.A., 2012. Carsharing in Shanghai, China: analysis of behavioral response to local survey and potential competition. Transp. Res. Rec. J. Transp. Res. Board 2319 (1), 86-95.

Washington, P., Karlaftis, M.G., Mannering, F., 2010. Statistical and Econometric Methods for Transportation Data Analysis, second ed. Chapman and Hall/CRC.

Wei, Q., 2019. Dynamic Pricing Solves the Urban Transportation Disparity - Evidence from NYC On-Demand Ride-Sharing Drivers. Available at SSRN: 〈http://dx.doi.org/10.2139/ ssrn.3422338>.

Weng, G.S., Zailani, S., Iranmanesh, M., Hyun, S.S., 2017. Mobile taxi booking application service's continuance usage intention by users. Transp. Res. Part D Transp. Environ. 57 $207-216$.

Yao, Z.G., Ding, X.D., 2011. Measuring passenger's perceptions of taxi service quality with weighted SERVPERF. Appl. Mech. Mater. 97-98, 1181-1184. https://doi.org/10.4028/ www.scientific.net/AMM.97-98.1181

Zeng, C., Oren, N., 2014. Dynamic taxi pricing. In: Proceedings of the Paper Presented at European Conference on Artificial Intelligence (ECAI-2014). Prague, United Kingdom, pp. 1135-1136. 〈10.3233/978-1-61499-419-0-1135〉.

Zhang, Y., Guo, H., Li, C., Wang, W., Jiang, X., Liu, Y., 2016. Which one is more attractive to traveler, taxi or tailored taxi? An empirical study in China. Procedia Eng. 137, 867-875. https://doi.org/10.1016/j.proeng.2016.01.327

Christina Milioti is an assistant professor at the Department of Civil Engineering of the University of West Attica, Greece.

Konstantinos Kepaptsoglou is an associate professor at the School of Rural and Surveying Engineering of the National Technical University of Athens, Greece.

Konstantinos Kouretas is a Ph.D. candidate at the School of Rural and Surveying Engineering of the National Technical University of Athens, Greece.

Eleni I. Vlahogianni is an associate professor at the School of Civil Engineering of the National Technical University of Athens, Greece. 